\title{
Conseqüências do uso de métodos anticoncepcionais na vida das mulheres: o caso da laqueadura tubária
}

\author{
Impact of contraceptive methods on women's \\ lives: the case of tubal ligation
}

Maria José Duarte Osis 1

Anibal Faúndes 2

Maria Helena de Sousa 1

Patricia Bailey 3

1 Centro de Pesquisa das Doenças Materno-Infantis de Campinas.

C. P. 6181, Campinas, SP

13081-970, Brasil.

2 Departamento de

Tocoginecologia,

Faculdade de Ciências

Médicas, Universidade

Estadual de Campinas.

C. P. 6181, Campinas, SP

13081-970, Brasil.

3 Family Health

International (FHI).

P. O. Box 13950, Research

Triangle Park, NC, 27709, USA
Abstract This study focused on the long-term consequences of tubal ligation on women's lives. Women 30 to 49 years old living in Campinas, State of São Paulo (Brazil), were interviewed: 236 sterilized at least five years prior to the interview and 236 non-sterilized women. Their experiences with the currently used contraceptive methods were compared with regard to sati sfaction, benefits, and damage attributed to the method, feelings of regret, and perception of effects on their health, body, menstruation, sex, affective and family life, job, studies, economic status, and self-esteem. Scores were created to compare the groups in relation to self-esteem, well-being/quality of life, relationship with partner, and gender issues. Satisfaction with the currently used contraceptive method was significantly higher among sterilized women, although they more fre quently reported having regretted being sterilized at some moment in ti me. Relatively more sterilized women felt that the contraceptive method had improved their sex lives and economic status, while producing a negative effect on their menstruation. No significant difference was observed between the groups with regard to the scores studied.

Key words Contraception; Tubal Sterilization; Family Planning

Resumo Investigaram-se as conseqüências da laqueadura tubária, a longo prazo, na vida de mulheres resi dentes em Campinas, São Paulo. Aplicando-se um questi onário estruturado e prétestado, entrevistaram-se mulheres de trinta a 49 anos de idade, 236 laqueadas há pelo menos cinco anos e o mesmo número de não laqueadas. Os grupos foram comparados quanto à sua satisfação com o método anticoncepci onal em uso, aos benefícios e prejuízos a ele atribuídos, ao possível arrependimento e à percepção de seus efei tos sobre a saúde, corpo, menstruações, vida sexual, afetiva efamiliar, trabalho, estudos, si tuação econômica e autoval oração. Criaram-se escores para comparar os grupos quanto a conhecimento sobre métodos anticoncepci onais, amor próprio/auto-estima/competência, bem-estar/qualidade de vida, relacionamento com o parceiro, questões de gênero. A satisfação com o método em uso foi significativamente maior entre as muIheres laqueadas, embora tenham si do as que mais referiram arrependimento. Estas também atribuíram mais freqüentemente ao método mel hora na vida sexual e na situação econômica; por outro lado, rel ataram um efei to negativo sobre suas menstruações. Não se verificaram diferenças si gni ficativas quanto aos escores avaliados.

Palavras-chave Anticoncepção; Esterilização Tubária; Planejamento Familiar 


\section{Introdução}

A laqueadura tubária é atual mente o método contraceptivo mais usado no Brasil: $40,1 \%$ das mulheres com idade entre 15 e 49 anos e que vivem em união estão laqueadas (BEM FAM/ M ACRO, 1997). O seu rápido crescimento chama a atenção, considerando que a prevalência em 1986 era de $27 \%$ (Arruda et al., 1987). Tomando-se como exemplo específico o caso do município de São Paulo, verifica-se que em 1965 havia $6,9 \%$ de esterilizadas entre as muIheres unidas de 15 a 49 anos de idade (Berquó $\&$ Oya, 1977), elevando-se essa proporção a 16\% em 1978 (Berquó, 1989), a 26,4\% em 1988 (Osis et al., 1991) e a 32\% em 1991 (Hardy et al., 1991).

Além da alta prevalência, a situação legal da ligadura de trompas foi ambígua até recentemente. Oficialmente, ela foi sancionada como método anticoncepcional apenas em novembro de 1997 (Brasil, 1997a, 1997b). Essa ambigüidade tem sido vista também como um fator associado às altas taxas de cesariana vigentes no país. Cinqüenta e nove por cento das muIheres esterilizadas, identificadas na última Pesquisa Nacional sobre Demografia e Saúde (PNDS), tinham sido laqueadas por ocasião de uma cesárea, muitas das quais, certamente, foram realizadas com o propósito exclusivo de fazer também a laqueadura (Hardy et al., 1993; BEM FAM/MACRO, 1997).

Os estudos que têm abordado a laqueadura vêm constantemente apontando a sua realização em mulheres bastante jovens e com poucos filhos. Também tem sido evidenciado o pagamento extra pela esterilização, que a mai oria das mulheres referia como necessário para obtê-la, antes de sua regulamentação legal, apesar da cirurgia ser realizada, principalmente, nos serviços públicos de saúde (Osis et al., 1991; Hardy et al., 1993; Berquó, 1994; BEMFAM/MACRO, 1997; Faúndes et al., 1998).

Quanto ao impacto da laqueadura, têm sido focalizados seus efeitos sobre o crescimento populacional, a chamada síndrome pós-laqueadura, e a questão do arrependimento. A sua alta prevalência é consistentemente apontada como sendo a principal responsável pela queda na taxa de crescimento populacional no Brasil nos últimos 30 anos: de $2,8 \%$ ao ano na década de 60 para cerca de 2,5\% nos anos 90 (Martine, 1996). Do ponto de vista clínico, a discussão sobre os possíveis efeitos da esterilização sobre as características menstruais das mulheres tem resultado em controvérsia, sem que, até o momento, os resultados possam ser considerados indiscutíveis (Hermann \& Souza,
1985; Alvarez et al., 1989; Rulin et al., 1989; Wilcox et al., 1992; Pollack, 1993).

Diversos estudos realizados no Estado de São Paulo têm indicado uma proporção de arrependimento entre 10 e $20 \%$ das mulheres laqueadas (Hardy et al., 1991; Barbosa et al., 1994; Vieira, 1994, 1998; Cecatti \& Faúndes, 1996). Além disso, esse fenômeno tem se tornado mais visível nos serviços de saúde, dada a demanda pela cirurgia de reversão (Bahamondes et al., 1992; Barbosa et al., 1994; Hardy et al., 1996). Apontam-se como os principais fatores de risco para o arrependimento a realização da operação antes dos 25 anos de idade, informação deficiente acerca da laqueadura, o menor número de métodos anticoncepcionais conhecidos, perda de filhos e troca de companheiro posteriormente à cirurgia (Hardy et al., 1996; Vieira, 1998).

Nos últimos anos, tem-se evidenciado a preocupação de estudar outras conseqüências da laqueadura na vida das mulheres, em termos de seu comportamento sexual e risco de contrair doenças sexual mente transmissíveis (DST ), especialmente a Síndrome da I munodeficiência Adquirida (AIDS), em relação à sua saúde em geral equanto a algumas possíveis alterações psicossociais (Barbosa \& Villela, 1995; Serruya, 1996). A abordagem desses aspectos apresenta para discussão outra ordem de questões relativas ao significado da esterilização cirúrgica na vida das mulheres.

No contexto de ambigüidade jurídica, suposta clandestinidade e conseqüente exploração econômica, que caracterizou a evolução da prevalência da laqueadura nas últimas duas décadas, para as mulheres pobres, ela chegou a ser representada como se fosse uma conquista, como uma elevação de posição social. Serruya (1996), estudando mulheres pobres esterilizadas em Belém do Pará, verificou em seu discurso a representação da laqueadura como uma conquista obrigatória para alcançar uma vida melhor. Na fala dessas pessoas, esterilizar-se implicava a equação necessária entre o desejo de ser mãe e as condições concretas para o exercício da maternidade.

A laqueadura também é representada como a única alternativa confiável, segura, de evitar uma nova gravidez (Osis et al., 1997). A necessidade da anticoncepção, claramente vivenciada pelas mulheres, contrapõe-se à angústia de não saber como controlar efetivamente a sua fecundidade, em vista de insucessos freqüentes, traduzidos no incômodo de suportar efeitos colaterais e, principalmente, em gravidezes indesejadas. O papel reprodutivo é socialmente imposto às mulheres, como se a responsabi- 
lidade fora unicamente sua, de maneira que os insucessos nessa área acabam sendo atribuídos à sua incapacidade pessoal de controlá-lo. Nesse contexto, a laqueadura aparece como a melhor opção. Por ser feita pelo médico, a sua eficácia se legitima e, ao mesmo tempo, absolve a mulher da culpa relativa às possíveis faIhas dos métodos anticoncepcionais (Serruya, 1996). Por outro lado, por ser um método permanente de contracepção, a esterilização pode colocar-se como uma negação da mulher enquanto reprodutora, negação dos papéis sociais de gênero, numa tentativa, nem sempre consciente, de assumir o poder sobre o seu próprio corpo, historicamente subordinado ao papel de mãe em potencial (Minella, 1998).

Tomando em consideração os aspectos acima referidos, o "fenômeno da laqueadura" no Brasil suscita questões quanto ao seu significado social. Seria um indicador de que as mulheres têm se apercebido da dominação de gênero e iniciaram um processo de desconstrução das relações de poder em que se acham inseridas? Caso isso esteja ocorrendo, a laqueadura poderia estar implicando maior autonomia e uma construção de relações de gênero mais eqüitativas na vida das mulheres a ela submetidas, cujos reflexos deveriam ser visíveis na qualidade de vida. Ou será que a opção pela laqueadura apresenta-se como inevitável frente à falta de alternativas acessíveis e percebidas como confiáveis?

Este trabalho apresenta resultados de um estudo que teve como objetivo investigar as conseqüências da laqueadura tubária, a longo prazo, na vida das mulheres, focalizando principalmente a sua percepção acerca do tema e alguns aspectos psicossociais que poderiam ou não estar sendo modificados na vigência da opção pela laqueadura.

\section{Sujeitos e métodos}

Foi realizado um estudo descritivo e comparativo, em que se entrevistaram 472 mulheres (metade laqueadas e metade não laqueadas), residentes no Município de Campinas, Estado de São Paulo, com idades entre 30 e 49 anos. 0 tamanho amostral foi calculado a partir de resultados obtidos por Vessey et al. (1983), que estudou um grupo de mulheres laqueadas e outro cujos maridos haviam sido vasectomizados, verificando uma taxa acumulada (aos seis anos de seguimento) de 6,9\% de desordens menstruais entre essas últimas. Estimou-se uma diferença de aproximadamente oito pontos percentuais entre essa taxa e a proporção de mu-
Iheres laqueadas com a mesma queixa; adotou-se $\alpha$ de 0,05 e $\beta$ de 0,20.

A amostragem foi feita por conglomerados, sorteando-se 100 setores censitários do Município de Campinas em que, segundo dados do Censo 91, a renda média era de, no máximo, 8,1 salários mínimos. Esses setores foram percorridos por entrevistadoras especialmente treinadas para a pesquisa, que receberam um mapa de cada setor em que deviam trabalhar e utilizaram uma ficha especialmente desenhada para registrar todos os endereços encontrados no percurso (casas, lojas, postos de gasolina, terrenos baldios, etc.) e todas as mulheres de 30 a 49 anos de idade moradoras no setor.

Cada setor era percorrido, a partir de uma esquina sorteada previamente, até que se completasse a sel eção e entrevista de dois ou três pares (uma laqueada e outra não laqueada) de mulheres elegíveis, conforme o tamanho do setor. Nesse processo, foram percorridos 7367 endereços; 2860 mulheres de 30-49 anos de idade foram identificadas; dessas, conseguiuse contactar 2474 mulheres, sendo que 2348 responderam a um check-list e 128 recusaramse a fazê-lo. Dentre as mulheres que responderam, 961 disseram ter feito laqueadura (794 há cinco ou mais anos antes), 1382 referiram não terem sido esterilizadas, três não sabiam informar e faltou informação de duas mulheres.

Em cada setor, ao identificar uma mulher elegível para o estudo (30 a 49 anos de idade), a entrevistadora solicitava autorização para aplicar-Ihe o referido check-list. Para cada mulher elegível era atribuído um check-list, mesmo que não estivesse em casa naquele momento, reservando-o para a ocasião em que fosse possível falar pessoalmente com ela. A seleção das mulheres para o estudo respeitou a ordem em que foram identificadas. Desta forma, a entrevistadora só podia selecionar uma mulher para o estudo quando não houvesse check-lists de resposta pendentes entre aquelas que a antecediam no percurso da entrevistadora. Sempre que uma mulher elegível não estava em casa, a entrevistadora retornava à casa dela e/ ou tentava fazer contato (por carta ou telefone), por pelo menos três vezes, em dias e horários diferentes. As mulheres que nunca se conseguiu contactar, apesar dessas três tentativas, foram consideradas como "perdidas" para o estudo.

Obedecidas as diretrizes acima explicitadas, em cada setor, a primeira mulher selecionada foi a primeira laqueada que cumpriu os critérios de inclusão, a partir da qual selecionaram-se as demais a serem entrevistadas. Para cada laqueada entrevistada, selecionava-se a primeira não laqueada identificada na se- 
qüência do percurso, que tinha não mais de dois anos de diferença de idade em relação à mulher esterilizada. Quando uma mulher cumpria os critérios de inclusão, era convidada a participar do estudo, lendo-se para ela o Termo de Consentimento Pós-Informação Oral. Caso ela aceitasse participar, a entrevista era feita imediatamente ou agendada, segundo sua conveniência. Cada mulher foi identificada no estudo apenas por um número, de maneira a preservar o sigilo das fontes de informação.

Para coletar os dados foi utilizado um questionário estruturado e pré-testado, compreendendo as seguintes seções: características sócio-demográficas e reprodutivas; auto-avaliação sobre experiência de vida; conhecimento e uso de métodos anticoncepcionais; auto-avaliação da experiência com o método. Para subsidiar o desenvolvimento das seções do questionário relativas à auto-avaliação da experiência de vida e com o método anticoncepcional utilizado, e parte da seção sobre conhecimento e uso de contracepção, foram realizados quatro grupos focais com mulheres de características semelhantes àquelas que, posteriormente, foram incluídas na amostra.

Grupos focais constituem uma técnica qualitativa para coleta de dados, utilizada quando se pretende captar as percepções, sentimentos e a maneira de pensar das pessoas em relação a um determinado tópico. Este é intensivamente focalizado através de um roteiro de perguntas, previamente redigidas e ordenadas (Krueger, 1994). Na presente pesquisa, os grupos focais foram realizados com o objetivo de captar a percepção das mulheres acerca do que consideravam que fosse amor-próprio/auto-esti$\mathrm{ma} /$ competência, bem-estar/ qualidade de vida, bem como sua opinião acerca do que pode ser considerado um bom ou mau relacionamento com o parceiro. Também se investigou sua opinião em relação (a) aos papéis sociais atribuídos a mulheres e homens no meio em que viviam, o que neste trabal ho se denomina de "questões de gênero"; e (b) às conseqüências para a vida das mulheres do uso de métodos anticoncepcionais (MAC), em geral, e, especificamente, da esterilização cirúrgica feminina.

A partir da análise dos grupos focais acima referidos foram preparados cinco conjuntos de frases que procuraram incorporar a percepção das mulheres acerca de cada um dos tópicos abordados no roteiro. Essas frases eram lidas para as entrevistadas e se solicitava que dissessem se concordavam ou discordavam. As frases foram redigidas tanto afirmando quanto negando resultados dos grupos focais. Por exemplo, um achado importante nos grupos focais foi a percepção das participantes de que "as mulheres nasceram para serem mães". Conseqüentemente, no conjunto de perguntas relativas às questões de gênero incluiu-se a frase " $A$ mulher nasceu para ser mãe". No conjunto de frases relativas aos MAC foram incluídas algumas afirmativas para avaliar o conhecimento das entrevistadas acerca dos métodos anticoncepcionais em geral e, especificamente, sobre a laqueadura. Os tópicos abordados nessas perguntas foram principalmente aqueles que chegaram a ser discutidos nos grupos focais, como, por exemplo, a idéia de que depois de sete anos ocorre espontaneamente a reversão da laqueadura.

Ainda tendo como parâmetro o que se observou nos grupos, elaborou-se um escore para cada conjunto, em que a pontuação máxima atribuída à resposta dada a cada frase correspondeu à perspectiva explicitada pelas mulheres como sendo a mais positiva e a mínima aos aspectos mais negativos na opinião delas.

A experiência das mulheres com o método anticoncepcional que estavam usando (ou com o que haviam usado por último) foi avaliada através de perguntas relativas à sua satisfação/ insatisfação, arrependimento ou não, e se elas atribuíam ao método mudanças em al gumas áreas de sua vida, e, em caso positivo, se consideravam as alterações para melhor ou para pior. As áreas sobre as quais se perguntou foram: saúde em geral, corpo, vida sexual, menstruações, relacionamento com marido ou companheiro, relacionamento familiar, trabal ho fora de casa, situação econômica e autovaloração. No grupo de mulheres não esterilizadas, 26 referiram nunca terem usado métodos anticoncepcionais e sete disseram não estar utilizando qualquer método por ocasião da entrevista porque haviam descoberto serem inférteis.

Para os procedimentos de análise dos dados utilizaram-se os programas SPSS-PC e EpiInfo 6.0. Primeiramente foi realizada uma análise bivariada descritiva da amostra, comparando-se os dois grupos - laqueadas e não laqueadas - quanto às características sócio-demográficas e reprodutivas estudadas. Para a comparação, no caso das tabelas $2 \times 2$ foram utilizados os testes Qui-quadrado com correção de Yates ou Exato de Fisher; para tabelas maiores utilizou-se o teste qui-quadrado de Pearson (Armitage, 1974). Em seguida, foram desenvolvidas análises bivariadas para comparar as muIheres laqueadas e não laqueadas quanto às seguintes variáveis dependentes: amor-próprio/ auto-estima/competência, bem-estar/qualidade de vida, relacionamento com o parceiro, questões de gênero, conhecimento sobre mé- 
todos anticoncepcionais em geral e especificamente sobre a laqueadura, e a percepção dos efeitos do uso de métodos anticoncepcionais em sua vida (efeitos sobre a saúde e o corpo em geral, bem como em outras áreas: menstrual, sexual, afetiva, familiar, trabalho, estudos, situação econômica, autovaloração). Para as variáveis avaliadas através de escores, estes foram definidos com base nos resultados dos grupos focais realizados para subsidiar a preparação do questionário, de maneira que, para cada conjunto de perguntas, quanto mais alta a pontuação obtida, melhor foi considerada a situação da mulher em relação à variável correspondente. Os escores foram trabalhados, em geral, definindo as categorias através dos quartis (primeiro quartil, mediana e terceiro quartil).

Em seguida, foram desenvolvidos modelos para análise múltipla por regressão logística (Hosmer \& Lemeshow, 1989), incluindo todas as mulheres, para estudar as relações entre cada uma das variáveis dependentes e o conjunto de variáveis preditoras:

\section{Dependentes}

- Amor-próprio/ auto-estima/competência (escore até 38 pontos: 0/ escore>38: 1)

- Bem-estar/qualidade de vida (escore até 19 pontos: 0/ escore>19: 1)

- Relacionamento com companheiro (escore até 47 pontos: 0/ escore>47: 1)

- Relações de gênero (escore até 28 pontos: 0/ escore>28: 1)

- Renda familiar per capita (até $\mathrm{R} \$ 300,00$ : 0/ >R\$300,00: 1)

- Alterações menstruais (sim: 1/não: 0)

- Mudança na vida sexual (melhor: 1/não mudou ou piorou: 0)

- Mudança na saúde (pior: 1/ não mudou ou melhorou: 0)

- Mudança no corpo (pior: 1/ não mudou ou melhorou: 0)

- Mudança no relacionamento com o marido/ companheiro (melhor: 1/não mudou ou piorou: 0)

- Mudança no valor que dá a si mesma (meIhor: 1/não mudou ou piorou: 0)

\section{Variáveis preditoras}

- Método utilizado (laqueadura: 1/ outro: 0)

- Escolaridade (até 8a série: 0/ >8a série: 1 )

- Idade da mulher na entrevista (anos)

- Estado marital (com companheiro: 0/sem companheiro: 1)

- Mulher trabalha no momento da entrevista (sim: 1/ não: 0)
- Número de gestações (até 2: 0/ >2: 1)

- Número de filhos nascidos vivos (até 3:

0/>3: 1)@

- Número de abortos (0/ $\geq 1: 1) @$

- Número de filhos vivos (até 2: 0/ >2: 1) @

- Religião (praticante: 1/não praticante: 0)

- Cor segundo a mulher (branca: 1/não branca: 0)

- Renda familiar (até R\$ 1200,00: 0/ > R 1200,00: 1)

- Renda “per capita” (até R\$ 300,00: 0/ >R\$ 300,00: 1)

- Conhecimento sobre métodos anticoncepcionais (escore até 4 pontos: 0/ escore>4: 1)

- Conhecimento sobre a laqueadura (escore até 4 pontos: 0/ escore $>4$ : 1 )

Para os escores, o ponto de corte utilizado foi a mediana. Com respeito às variáveis assinaladas com @, as mulheres que nunca engravidaram (39) foram consideradas na análise como tendo nenhum aborto, nenhum filho nascido vivo e nenhum filho vivo no momento da entrevista.

Para caracterizar a amostra do ponto de vista sócio-econômico foi utilizado o sistema proposto pela Associação Brasileira de Institutos de Pesquisa de Mercado (Abipeme) e Associação Brasileira de Anunciantes (Aba), de 1991 (Almeida \& Wickerhauser, 1991). Quanto a esse aspecto, os grupos estudados revelaram-se homogêneos. A maioria das entrevistadas (64,9\% das laqueadas e 71,4\% das não laqueadas) pertenciam às classes C, D e E. Ao comparar a classificação de status sócio-econômico das muIheres selecionadas com as demais, que também responderam ao check-list mas não participaram do estudo, não se verificou diferença: $68 \%$ das selecionadas e das não selecionadas pertenciam às classes $C, D, E$.

Observando-se a amostra, verificou-se que os grupos estudados também foram homogêneos quanto às características sócio-demográficas: a média de idade das mulheres laqueadas foi de 41,8 anos e das não laqueadas foi de 41,7 anos; $68 \%$ nos dois grupos tinham completado, no máximo, o primeiro grau de escolaridade; cerca de $72 \%$ das entrevistadas se autoidentificaram como brancas, enquanto $16 \%$ das laqueadas e $19 \%$ das demais se auto-identificaram como negras; eram católicas praticantes (freqüentavam a igreja pelo menos uma vez por mês); perto de 35\% de todas as mulheres e $19 \%$ das laqueadas puderam ser classificadas como protestantes/ evangélicas praticantes, o que se observou para $14 \%$ das mulheres não esterilizadas. Pouco mais da metade das muIheres, nos dois grupos, estava realizando trabalho remunerado por ocasião da entrevista. 


\section{Resultados}

Em torno de 85\% das mulheres em ambos grupos referiu que o último método anticoncepcional utilizado (MAC) trouxe benefícios à sua vida. Uma pequena proporção, mas quase duas vezes maior entre as não laqueadas, referiu que o último MAC produzira prejuízos. Essas diferenças não foram significativas. Quanto à satisfação com o uso do MAC, as diferenças entre os grupos foram significativas: mais da metade $(55,3 \%)$ das laqueadas e $30 \%$ das demais manifestaram-se como estando muito satisfeitas. No outro extremo, menos de $10 \%$ das laqueadas e pouco mais de $20 \%$ das outras entrevistadas declararam estar pouco satisfeitas ou insatisfeitas. Observaram-se resultados opostos com respeito a alguma vez ter-se arrependido de haver escolhido o MAC em questão. A porcentagem de laqueadas $(13,6 \%$ ) que referiu arrependimento foi duas vezes maior que a das usuárias de outros métodos $(6,4 \%)$, sendo a diferença estatisticamente significativa (Tabela 1).

Houve duas áreas da vida das mulheres em que se observaram mais mudanças para meIhor entre as laqueadas do que entre as demais. Em duas outras áreas observou-se o oposto. Duas vezes mais entrevistadas que haviam sido esterilizadas relataram melhora na vida sexual

Tabela 1

Distribuição percentual das mulheres segundo auto-avaliação acerca do que a utilização do último método anticoncepcional trouxe para sua vida, grau de satisfação com o método e arrependimento, ou não, por tê-lo escolhido.

\begin{tabular}{lccc}
\hline Variáveis & Laqueadas & Não laqueadas\# & $p$ \\
\hline O uso do método trouxe & & & 0,605 \\
Benefícios & 86,6 & 84,5 & \\
Prejuízos & 5,2 & 9,0 & \\
Um pouco de cada & 8,2 & 6,5 & \\
Total de mulheres* & 232 & 200 & $<0,001$ \\
& & & \\
Grau de satisfação & 55,3 & 30,0 & \\
Muito satisfeita & 35,3 & 49,3 & \\
Satisfeita & 3,8 & 10,3 & $<0,03$ \\
Pouco satisfeita & 5,5 & 10,3 & \\
Insatisfeita & 235 & 203 & \\
Total de mulheres** & & & \\
& & 6,4 & \\
Arrependimento & 13,6 & 93,6 & \\
Sim & 86,4 & 203 & \\
Não & 236 & & \\
Total de mulheres &
\end{tabular}

\# 26 nunca usaram métodos e sete referiram infertilidade.

* Quatro laqueadas e três não laqueadas não sabiam avaliar.

** Uma laqueada não soube avaliar.
( $13,6 \%$ comparadas a $6,9 \%$ de usuárias de outros $\mathrm{MAC}$ ) e a referência à mel hora na situação econômica foi quatro vezes mais freqüente no grupo de laqueadas ( $11,9 \%$ versus $2,5 \%$ no outro grupo). Essas diferenças foram significativas. Entretanto, não houve diferenças entre os grupos com respeito à porcentagem de mulheres que relatou piora nessas duas áreas (Tabela 2). Na análise múltipla por regressão logística, o fato de estar laqueada e a maior escolaridade associaram-se positivamente à menção de meIhora na vida sexual (Tabela 3).

Por outro lado, uma mudança positiva nas menstruações foi apontada por maior porcentagem de usuárias de outros métodos (16,3\%) comparadas às mulheres esterilizadas (11\%), mas não se constatou diferença estatística entre os grupos. Mais de um terço das mulheres que haviam sido esterilizadas (36\%) disseram ter experimentado mudanças para pior em suas menstruações, que atribuíam ao método, comparadas a $11,3 \%$ das entrevistadas do outro grupo. Essa diferença foi significativa e, quando se realizou a análise múltipla, verificou-se que a laqueadura estava diretamente associada às mulheres referirem alterações menstruais, enquanto a idade por ocasi ão da entrevista associou-se negativamente (Tabela 3 ). $\mathrm{Na}$ área da saúde em geral, houve uma diferença de quatro pontos percentuais a favor de outros métodos quanto à referência de melhora, enquanto no relato de piora a porcentagem de laqueadas foi quatro pontos maior, sem que, entretanto, se atingisse significação estatística (Tabela 2).

Não se observaram diferenças estatísticas entre os grupos estudados quanto aos escores de amor-próprio/auto-estima/competência, bem-estar/ qualidade de vida, relacionamento com o parceiro e questões de gênero. Pouco mais da metade entre as laqueadas $(54,6 \%$ ) e cerca da metade do outro grupo $(50,9 \%)$ obtiveram entre 35 e 42 pontos no escore de amorpróprio, de um total possível de 48. Cerca de um terço das entrevistadas nos dois grupos (34,5\% de laqueadas e $33,3 \%$ de não laqueadas) somaram no máximo 16 pontos no escore de qualidade de vida, de um total possível de 34 . Exatamente $50 \%$ das laqueadas e quase metade das não laqueadas somaram 48 ou mais pontos no escore de relacionamento com o parceiro (máximo de 64 pontos). Nas questões de gênero (máximo de 36 pontos), 30,2\% das mulheres esterilizadas e $20,8 \%$ das demais obtiveram, no máximo, 24 pontos no escore (Tabela 4). $\mathrm{Na}$ análise múltipla por regressão logística não se verificou que a laqueadura estivesse associada a qualquer das variáveis psicossociais estudadas (Tabela 5). 
Mudanças para melhor e pior em algumas áreas da vida, atribuídas pelas mulheres ao uso do método anticoncepcional (em percentagem).

\begin{tabular}{|c|c|c|c|c|c|c|}
\hline \multirow[t]{2}{*}{ Áreas } & \multicolumn{3}{|c|}{ Para melhor } & \multicolumn{3}{|c|}{ Para pior } \\
\hline & Laqueadura & $\begin{array}{l}\text { Outros } \\
\text { métodos\# }\end{array}$ & $\mathrm{p}$ & Laqueadura & $\begin{array}{l}\text { Outros } \\
\text { métodos\# }\end{array}$ & $\mathrm{p}$ \\
\hline Saúde* & 1,7 & 5,4 & NS & 15,3 & 10,8 & NS \\
\hline Corpo & 2,1 & 4,4 & NS & 14,4 & 12,8 & NS \\
\hline Vida sexual & 13,6 & 6,9 & $<0,04$ & 7,2 & 7,9 & NS \\
\hline Menstruações* & 11,0 & 16,3 & NS & 36,0 & 11,3 & $<0,001$ \\
\hline $\begin{array}{l}\text { Relacionamento } \\
\text { c/parceiro }\end{array}$ & 10,2 & 7,9 & NS & 2,5 & 5,4 & NS \\
\hline $\begin{array}{l}\text { Relacionamento } \\
\text { c/a família }\end{array}$ & 3,8 & 1,5 & NS & 2,5 & 1,5 & NS+ \\
\hline Trabalho fora de casa & 2,1 & 1,0 & NS & 0,4 & 0,5 & NS+ \\
\hline Situação econômica & 11,9 & 2,5 & $<0,001$ & 0,4 & 1,5 & NS+ \\
\hline Autovalor & 9,3 & 6,4 & NS & 4,2 & 1,5 & NS \\
\hline Total de mulheres & 236 & 203 & & 236 & 203 & \\
\hline
\end{tabular}

\# 26 nunca usaram métodos e sete referiram infertilidade.

* Faltou informação de uma mulher laqueada.

+ Teste exato de Fisher.

\section{Discussão}

A auto-avaliação das mulheres quanto à sua experiência com o método utilizado revelou uma maior satisfação das laqueadas, apesar de serem elas as que mais referiram al guma vez terem se arrependido de haver escolhido o método. Voltando aos resultados dos grupos focais, real izados previamente à coleta de dados para subsidiar a preparação do questionário utilizado na pesquisa, é possível estimar que, provavelmente, a satisfação das mulheres com a laqueadura esteja associada à principal razão pela qual o método foi escolhido: a percepção de que a esterilização dá a segurança de não engravidar. Esse achado concorda com o que Serruya (1996) apontou para as mulheres de Belém do Pará, para as quais a obtenção da laqueadura era vista como o fim de uma guerra, a da batal ha cotidiana que as mulheres travam para controlar sua fecundidade. A mesma perspectiva foi também observada por Minella (1998) entre mulheres esterilizadas de Florianópolis, SC, bem como em outro estudo, realizado em Campinas, SP (Costa et al., 1995), com mulheres que recentemente haviam sido esterilizadas, as quais consideravam a laqueadura como fator tranqüilizante, que as desobrigava da preocupação diária com a anticoncepção.

$\mathrm{O}$ arrependimento, entendido de forma ampla como uma sensação de que se gostaria de voltar atrás, não parece afetar a satisfação com o método. Parece, antes, por um lado, fazer parte da ambigüidade que caracteriza a anticoncepção no imaginário feminino, envolvendo o dilema da maternidade (Serruya, 1996); por outro lado, pode estar inserido exatamente no processo através do qual as mulheres chegam à laqueadura, ou seja, o arrependimento pode constituir-se em uma conseqüência da forma contingente como as mulheres chegam à decisão de laquear-se (porque já têm muitos fiIhos). Mas justamente por esse contexto em que surge o arrependimento é que ele acaba por não diminuir a satisfação das mulheres com a esterilização, porque acreditam que esta Ihes dá a certeza de não engravidarem.

Esta "crença” popular na eficácia absoluta da laqueadura tubária e na fal ha de qualquer outro método contrasta com as evidências que mostram uma taxa de gravidez não desprezível entre as mulheres laqueadas (Peterson et al., 1996) e uma alta eficácia anticoncepcional, semelhante à da laqueadura, de métodos reversíveis, como o Dispositivo Intra-Uterino (DIU) T de cobre 380 e o acetato de medroxiprogesterona de depósito - Depo-provera (Hatcher et al., 1989). Tal situação ilustra a dificuldade em socializar o conhecimento científico e a incapacidade dos pesquisadores difundirem seus achados na sociedade, onde poderiam ter aplicação prática.

Com respeito às mudanças atribuídas pelas mulheres à laqueadura, é interessante destacar 
Fatores associados às variáveis dependentes sobre percepção de mudanças em algumas áreas da vida das mulheres, atribuídas ao método em uso*.

\begin{tabular}{|c|c|c|c|c|}
\hline Variáveis & Coef. & E.P. Coef. & $\mathrm{p}$ & OR \\
\hline \multicolumn{5}{|l|}{ Alterações menstruais [ $\mathrm{n}=370$ ] } \\
\hline Método utilizado (laqueadura) & 0,869 & 0,226 & $<0,001$ & 2,38 \\
\hline Idade da mulher & $-0,080$ & 0,023 & $<0,001$ & 0,92 \\
\hline Constante & 2,376 & 0,958 & 0,013 & \\
\hline \multicolumn{5}{|c|}{ Mudança para melhor na vida sexual $[n=371]$} \\
\hline Método utilizado (laqueadura) & 0,910 & 0,375 & 0,015 & 2,48 \\
\hline Escolaridade (> 8ạ série) & 0,767 & 0,344 & 0,026 & 2,15 \\
\hline Constante & $-3,020$ & 0,355 & $<0,001$ & \\
\hline \multicolumn{5}{|c|}{ Mudança para pior na saúde [ $n=369$ ] } \\
\hline Religião (praticante) & 0,715 & 0,348 & 0,040 & 2,04 \\
\hline Renda familiar $(>\mathrm{R} \$ 1200,00)$ & $-0,673$ & 0,331 & 0,042 & 0,51 \\
\hline Constante & $-2,117$ & 0,314 & $<0,001$ & \\
\hline \multicolumn{5}{|c|}{ Mudança para pior no corpo $[\mathrm{n}=369]$} \\
\hline Idade da mulher & $-0,032$ & 0,006 & $<0,001$ & 0,97 \\
\hline Cor branca segundo a mulher & $-0,805$ & 0,317 & 0,011 & 0,45 \\
\hline \multicolumn{5}{|c|}{$\begin{array}{l}\text { Mudança para melhor no relacionamento } \\
\text { com o companheiro }[n=365]\end{array}$} \\
\hline Renda familiar (>R\$ 1200,00$)$ & 1,082 & 0,388 & 0,005 & 2,95 \\
\hline Constante & $-2,861$ & 0,325 & $<0,001$ & \\
\hline \multicolumn{5}{|c|}{$\begin{array}{l}\text { Mudança para melhor no valor que dá } \\
\text { a si mesma }[n=371]\end{array}$} \\
\hline Religião (praticante) & 0,948 & 0,445 & 0,033 & 2,58 \\
\hline Constante & $-3,065$ & 0,387 & $<0,001$ & \\
\hline
\end{tabular}

* Análise múltipla por regressão logística.

que, significativamente, mais laqueadas atribuíram ao método melhora na vida sexual, uma associação que se confirmou na análise múltipla. Esse achado pareceria confirmar a hipótese de que a laqueadura liberaria a mulher para ter uma vida sexual melhor. Entretanto, é preciso interpretar esse aspecto com cautela porque o resultado foi obtido a partir de perguntas fechadas, sem que se pudesse aprofundar o que as mulheres estavam entendendo por meIhora na vida sexual. Alguns estudos com muIheres laqueadas (Barbosa \& Villela, 1995; Serruya, 1996) apontaram que a expectativa delas seria de maior liberdade sexual, o que não se confirma depois da esterilização. Em nosso estudo, porém, se retomarmos os resultados dos grupos focais prévios e o conjunto dos resultados obtidos, podemos entender que, possivelmente, quando as mulheres atribuem à laqueadura uma melhora em sua vida sexual, esta- riam se referindo a algo bem menos abrangente que uma liberação sexual; estariam, quiçá, fazendo referência a que a laqueadura, pela segurança de não engravidar, Ihes daria uma vida sexual menos atemorizada.

As alterações menstruais atribuídas ao uso do MAC, muito mais referidas pelas laqueadas, suscita mais uma vez a freqüente discussão acerca dos efeitos da laqueadura sobre o padrão menstrual, que tem sido, do ponto de vista clínico, um assunto bastante controverso na literatura (Bordahl, 1984; De Stefano et al., 1985; Rulin et al., 1989; Wilcox et al., 1992; Pollack, 1993). Em nosso caso, porém, trata-se da percepção das mulheres e não da constatação clínica de um fenômeno. E, por este prisma, em nossa amostra, fica claro que as mulheres laqueadas percebem e atribuem à esterilização cirúrgica significativamente mais alterações menstruais do que as mulheres do grupo de 
comparação. Uma possível explicação para essa percepção das mulheres, a par das explicações clínicas e considerando que a principal queixa mencionada foi o aumento de fluxo, pode ser o fato de que boa parte das laqueadas teriam sido previamente usuárias de pílula, de forma que a menstruação sem o uso de hormônios pareceu excessiva, se comparada à que tinham anteriormente. Os dados desta pesquisa, entretanto, não permitem afirmar nem descartar que existam maiores alterações menstruais entre as mulheres laqueadas. Apenas é possível dizer que, segundo a percepção das mulheres, a laqueadura foi acompanhada por alterações menstruais em uma alta porcentagem dos casos. Por outro lado, uma vez que a idade por ocasião da entrevista esteve inversamente associada à referência de alterações menstruais, pode-se pensar que, na medida em que as muIheres tenham mais idade, menos elas relatam mudanças menstruais atribuídas ao uso de um contraceptivo, quiçá porque, caso as experimentem, acreditem que elas sejam devidas ao envelhecimento.

Considerando o conjunto de nossos resultados e comparando-os com outros estudos cujo enfoque foi similar (Serruya, 1996; Minella, 1998), verifica-se que, no geral, a laqueadura tubária é vista de forma bastante positiva pelas mulheres que passam por ela, apesar de apontarem alguns efeitos negativos e reconhecerem que esses as incomodam. Entretanto, no balanço entre o custo - aquilo que desagrada e o benefício - não engravidar - preval ece este último. Esta constatação, mais uma vez, aponta para a falta de conhecimento real e correto de alternativas contraceptivas reversíveis que estejam acessíveis às mulheres no Brasil.

Em geral, os estudos que tratam do conhecimento de métodos anticoncepcionais pela população revelam altas porcentagens de muIheres e homens que declaram conhecer boa parte dos métodos, especialmente aqueles considerados de alta eficácia, e que, teoricamente, estão disponíveis no país (Pinotti et al., 1990; Berquó, 1994; BEMFAM/MACRO, 1997; Vieira, 1998). Porém, esses estudos referem-se a conhecimento de métodos em termos de "ouvir falar" e não medem a qualidade da informação que as pessoas dizem possuir acerca de cada método. É possível que pesquisas que aprofundem essa questão revelem que muitas das pessoas que dizem conhecer vários MAC pouco sabem ou têm conceitos muito errôneos acerca das características, eficácia e efeitos colaterais da maior parte dos MAC. Isso, poderia explicar as características da prevalência de anticoncepcionais no Brasil, quase que absolutamente
Tabela 4

Distribuição percentual das mulheres segundo alguns escores definidos e método utilizado.

\begin{tabular}{|c|c|c|c|}
\hline Escores & Laqueadas & Não laqueadas & $p^{*}$ \\
\hline $\begin{array}{l}\text { Amor-próprio/auto-estima/ } \\
\text { competência }\end{array}$ & & & 0,824 \\
\hline Até 34 & 24,5 & 26,3 & \\
\hline $35-38$ & 28,8 & 24,6 & \\
\hline $39-42$ & 25,8 & 26,3 & \\
\hline$\geq 43$ & 21,0 & 22,8 & \\
\hline Média (D. P.) & $37,2(6,9)$ & $37,8(6,4)$ & \\
\hline Total de mulheres & 233 & 228 & \\
\hline Bem-estar/qualidade de vida & & & 0,357 \\
\hline Até 16 & 34,5 & 33,3 & \\
\hline $17-19$ & 23,3 & 20,3 & \\
\hline $20-22$ & 20,7 & 19,9 & \\
\hline$\geq 23$ & 21,6 & 26,4 & \\
\hline Média (D. P.) & $18,5(5,1)$ & $19,1(4,9)$ & \\
\hline Total de mulheres & 232 & 231 & \\
\hline Relacionamento com parceiro & & & 0,945 \\
\hline Até 36 & 29,6 & 26,0 & \\
\hline $37-47$ & 20,4 & 25,3 & \\
\hline $48-53$ & 24,7 & 24,7 & \\
\hline$\geq 54$ & 25,3 & 24,0 & \\
\hline Média (D. P.) & $43,4(12,7)$ & $44,9(10,9)$ & \\
\hline Total de mulheres & 186 & 146 & \\
\hline Questões de gênero & & & 0,174 \\
\hline Até 24 & 30,2 & 20,8 & \\
\hline $25-28$ & 30,7 & 34,2 & \\
\hline $29-32$ & 25,7 & 32,2 & \\
\hline$\geq 33$ & 13,4 & 12,8 & \\
\hline Média (D. P.) & $27,7(5,4)$ & $28,8(4,7)$ & \\
\hline Total de mulheres & 202 & 149 & \\
\hline
\end{tabular}

* Teste qui-quadrado de Mantel-Haenszel para associação linear.

dividida entre laqueadura e pílula, que são os métodos aos quais, popularmente, se atribui maior eficácia.

Por outro lado, a avaliação dos escores relativos às variáveis psicossociais foi expressiva ao não apontar a esterilização (eo uso de MAC em geral) como sendo rel evante para melhorar ou piorar a experiência das mulheres nos relacionamentos sociais e consigo mesmas. Ou seja, existem outros fatores que se sobrepõem ao fato da mulher estar laqueada ou não e que seriam mais importantes para determinar alterações em suas vivências em sociedade e consigo mesmas. Também neste aspecto, nossos resultados são coerentes com os de outros estudos que apontaram que a laqueadura constitui-se, 
Fatores associados a alguns escores, identificados na análise múltipla por regressão logística.

\begin{tabular}{|c|c|c|c|c|}
\hline Escores & Coef. & E. P. Coef. & $\mathrm{p}$ & OR \\
\hline \multicolumn{5}{|l|}{ A mor-próprio/auto-estima/competência } \\
\hline (corte em 38 pontos) $[n=380]$ & \multicolumn{4}{|c|}{ sem variáveis associadas } \\
\hline \multicolumn{5}{|l|}{ Bem-estar/qualidade de vida } \\
\hline \multicolumn{5}{|l|}{ (corte em 19 pontos) $[n=383]$} \\
\hline Renda “per capita” (> R\$ 300) & 1,130 & 0,230 & $<0,001$ & 3,09 \\
\hline Mulher trabalha & 0,582 & 0,225 & 0,010 & 1,79 \\
\hline Número de filhos nascidos vivos $(>3)$ & $-0,857$ & 0,362 & 0,018 & 0,42 \\
\hline Constante & $-1,002$ & 0,208 & $<0,001$ & \\
\hline \multirow{2}{*}{\multicolumn{5}{|c|}{$\begin{array}{l}\text { Relacionamento com companheiro } \\
\text { (corte em } 47 \text { pontos) }[n=274]^{\#}\end{array}$}} \\
\hline & & & & \\
\hline Escolaridade (> 8a série) & 0,985 & 0,315 & $<0,002$ & 2,68 \\
\hline Número de gestações (> 2) & $-0,719$ & 0,274 & 0,009 & 0,49 \\
\hline Renda per capita (> R\$300) & 0,925 & 0,301 & $<0,003$ & 2,52 \\
\hline Idade da mulher & $-0,076$ & 0,029 & 0,009 & 0,93 \\
\hline Constante & 2,906 & 1,181 & 0,014 & \\
\hline \multicolumn{5}{|l|}{ Questões de gênero } \\
\hline \multicolumn{5}{|l|}{ (corte em 28 pontos) $[n=292] \#$} \\
\hline Mulher trabalha & $-0,739$ & 0,249 & 0,003 & 0,48 \\
\hline Número de gestações (>2) & $-0,531$ & 0,250 & 0,034 & 0,59 \\
\hline Idade da mulher & $-0,052$ & 0,026 & 0,044 & 0,95 \\
\hline Constante & 2,458 & 1,097 & 0,025 & \\
\hline
\end{tabular}

\#A variável estado marital foi excluída do modelo por ser constante para esses casos.

por vezes, em uma espécie de ilusão das muIheres em conquistarem melhores condições de vida e maior "empoderamento" nas relações sociais (Barbosa \& Villela, 1995; Serruya, 1996).

Essa situação, portanto, faz refletir acerca da necessidade de mudar a abordagem do problema que pode representar uma prevalência de esterilização cirúrgica tão alta quanto a que se verifica no Brasil. Especialmente neste momento, em que, finalmente, a esterilização está sendo tratada pelas vias legais, apresenta-se a necessidade de efetivamente disponibilizar, pa- ra mulheres e homens, a mais ampla gama possível de métodos contraceptivos. Esse processo de disponibilização deve, necessariamente, incluir como componente principal a informação correta, atraente e significativa sobre as alternativas à laqueadura. É preciso que se pensem maneiras de atingir o imaginário da população com respeito à contracepção, de forma que seja possível suscitar credibilidade em outros métodos, essa mesma credibilidade de que desfruta a laqueadura entre as mulheres que querem evitar uma gravidez.

\section{Agradecimentos}

Os autores agradecem o suporte financeiro que a pesquisa, cujos resultados são parcialmente apresentados neste trabalho, recebeu como parte do Women's Studies Project no Brasil, da U.S. Agency of International Development (USAID), através de Family Health International (FHI). 
ALMEIDA, P. M. \& WICKERHAUSER, H., 1991. O Critério ABA/ABIPEME - Em Busca de uma Atualização. São Paulo: Associação Brasileira de Anunciantes (ABA)/ Associação Brasileira dos Institutos de Pesquisa de Mercado (ABIPEM).

ARMITAGE, P., 1974. Statistical Methods in Medical Research. New York: John Wiley and Sons.

ALVAREZ, F.; FAÚNDES, A.; BRACHE, V.; TEJADA, A. S. $\&$ SEGAL, S., 1989. Prospective study of the pituitary-ovarian function after tubal sterilizarion by the Pomeroy or Uchida techniques. Fertility and Sterility, 51:604-608.

ARRUDA, J. M.; RUTENBERG, N.; MORRIS, L. \& FERRAZ, E. A., 1987. Pesquisa Nacional Sobre Saúde Materno-Infantil ePlanejamento Familiar: Brasil, 1986. Rio de Janeiro: Sociedade Civil Bem-Estar Familiar no Brasil (BEMFAM)/Instituto para Desenvolvimento de Recursos (IRD).

BAHAM ONDES, L.; PETTA, C. A.; FAÚNDES, A.; DIAZ, J. \& BEDONE, A., 1992. Significado do recente aumento do número de solicitações de reversão de laqueadura em um serviço de esterilidade. Femina, 20:36-362.

BARBOSA, C. P.; PELLINI, E. A. J.; REIS, A. V.; SATO, M.; LESSER, R.; MARQUES, R. S. \& ANTI, S. M. A., 1994. Avaliação do grau de insatisfação pós-laqueadura tubária em São Bernardo do Campo. Reprodução, 9:159-162.

BARBOSA, R. M. \& VILLELA, W. V., 1995. Sterilization and sexual behaviour among women in São Paulo, Brazil. Reproductive Health Matters, 5:3746.

BEM FAM / M ACRO (Sociedade Civil Bem - Estar Familiar no Brasil/ Programa de Pesquisas de Demografia e Saúde Macro International Inc.), 1997. Pesquisa Nacional sobre Demografia eSaúde, 1996. Rio de Janeiro: BEMFAM/M ACRO.

BERQUÓ, E., 1994. Esterilização e raça em São Paulo. Revista Brasileira de Estudos Populacionais, 11: 19-26.

BERQUÓ, E., 1989. A esterilização feminina no Brasil hoje. In: Encontro Internacional "Saúde da MuIher: Um Direito a Ser Conqui stado". Campinas: Núcleo de Estudos Populacionais da Universidade Estadual de Campinas (NEPO/UNICAMP). (mimeo.)

BERQUÓ, E. \& OYA, D. T., 1977. A esterilização feminina. In: A Fecundidadeem São Paulo: Características Demográficas, Bi ológi cas e Sócio-Econômicas (E. Berquó, M. C. A. F. Oliveira \& C. P. F. Camargo, ed.), pp. 1-16, São Paulo: Centro Brasileiro de Análise e Planejamento (CEBRAP)/Editora Brasileira de Ciências.

BORDAHL, P. E., 1984. The social and gynecological long-term consequences of tubal sterilization. Acta Obstetricia et Gynaecologica Scandinavica, 63:487-495.

BRASI L, 1997a. Lei ordinária no 9263, de 12 de janeiro de 1996. Regula o parágrafo 7 do artigo 226 da constituição federal, que trata do planejamento familiar, estabelece penalidades e dá outras providências. Partes vetadas correspondentes aos artigos 10, 11, 14 e 15. Brasília: Diário Oficial da União, 20 de agosto de 1997, p. 17989, col. 1.
BRASI L, 1997b. Ministério da Saúde/ Secretaria de Assistência à Saúde. Portaria no 144, de 20 de novembro de 1997. Brasília: Diário Oficial da União, 24 de novembro de 1997, no 227, seção I, p. 27409.

CECATTI, J. G. \& FAÚ NDES, A., 1996. O Impacto das Altas Taxas de Cesariana sobrea Fecundidade de uma População. Um Estudo de Coorte Retrospectiva em Campinas, Brasil. Relatório técnico final apresentado à Fundação Ford. Campinas: Centro de Pesquisa das Doenças Materno-Infantis de Campinas (CEMICAMP).

COSTA, R. G.; OSIS, M. J. D. \& HARDY, E., 1995. Processo de Decisão pela Laqueadura entre Mulheres Laqueadas no Centro de Assistência Integral à Saúde da Mulher. Relatório Final. Campinas: Centro de Pesquisa das Doenças Materno-Infantis de Campinas (CEMICAMP).

DE STEFANO, F.; PERLM AN, M. D.; PETERSON, H. B. \& DIAM OND, E. L., 1985. Long-term risk of menstrual disturbances after tubal sterilization. American Journal of Obstetrics and Gynecology, 152: 835-841.

FAÚ NDES, A.; COSTA, R. G.; PÁDUA, K. S. \& PERDIGÃO, A. M., 1998. Associação entre prevalência de laqueadura tubária e características sócio-demográficas de mulheres e seus companheiros no Estado de São Paulo, Brasil. Cadernos de Saúde Pública, 14 (Sup. 1):49-57.

HARDY, E.; OSIS, M. J. D.; COSTA, R. G.; RODRIGUES, T. \& MORAES, T. M., 1991. Reavaliação do Programa de Assistência Integral à Saúde da Mulher no Estado de São Paulo. Relatório 1. Campinas: Centro de Pesquisas das Doenças Materno-Infantis de Campinas (CEMICAMP).

HARDY, E.; OSIS, M. J. D.; FAÚNDES, A.; ALVES, G. \& PINOTTI, J. A., 1993. A laqueadura tubárea precoce e durante cesárea. Dimensões atuais e fatores que a determinam. Revista Brasileira de Ginecologia eObstetrícia, 4:70-76.

HARDY, E.; BAHAM ONDES, L.; OSIS, M. J. D.; COSTA, R. G. \& FAÚNDES, A., 1996. Risk factors for tubal sterilization, detectable before surgery. Contraception, 54:159-162.

HATCHER, R. A.; KOWAL, D.; GUEST, F. J.; TRUSSEL, J.; STEWART, F. H.; STEWART, G. K.; BOWEN, S. C. \& CATES J r., W., 1989. Contraceptive Technology. Atlanta: Printed Matter.

HERMANN, V. \& SOUZA, G. A., 1985. Síndrome póslaqueadura. Femina, 13:845-849.

HOSMER, D. W. \& LEMESHOW, S., 1989. Applied Statistical Regression. New York: John Wiley and Sons.

KRUEGER, R. A., 1994. Focus Groups. A Practical Guide for Applied Research. Thousand Oaks: Sage Publications.

MARTINE, G., 1996. Brazil's fertility decline, 1965-95: a fresh look at key factors. Population and Development Review, 22:47-75.

MINELLA, L. S., 1998. Aspectos positivos e negativos da esterilização tubária do ponto de vista de muIheres esterilizadas. Cadernos de Saúde Pública, 14 (Sup. 1):69-79.

OSIS, M. J. D.; HARDY, E. E.; SIMÕES, I. R. S.; VERA, S. \& FAÚNDES, A., 1991. Laqueadura tubária nos serviços de saúde do Estado de São Paulo. Revista 
de Ginecologia e Obstetrícia de São Paulo, 1:195204.

OSIS, M. J. D.; COSTA, R. G.; DUARTE, G. A. \& FAÚNDES, A., 1997. O que as mulheres pensam sobre a laqueadura tubária. XV Reunión de la Associación Latinoamericana de Investigadores en Reproducción Humana (ALIRH), Resúmenes, pp. 3940, Cusco: ALIRH.

PETERSON, H. B.; ZHISEN, X.; HUGHES, J. M. WILCOX, L. S.; TYLOR, L. R. \& TRUSSEL, J., 1996. The risk of pregnancy after tubal sterilization: Findings from the U. S. Collaborative Review of Sterilization. American Journal of Obstetrics and Gynecology, 174:1161-1170.

PINOTTI, J. A.; FAÚ NDES, A.; HARDY, E.; SIMÕES, I. R.; OSIS, M. J. D.; SOUZA, T. R. \& MORAES, T. M., 1990. Avaliação da assistência ginecológica no Estado de São Paulo. Revista deGinecologia eObstetrícia de São Paulo, 1:7-21.

POLLACK, A. E., 1993. Esterilización masculina y femenina: Consecuencias a largo plazo para la salud. Outlook, 11:1-8.
RULIN, M. C.; DAVIDSON, A. R.; PHILLIBER, S. G.; GRAVES, W. L. \& CUSHMAN, L. F., 1989. Changes in menstrual symptoms among sterilized and comparison women: A prospective study. Obstetrics and Gynecology, 74:149-154.

SERRUYA, S., 1996. Mulheres Esterilizadas: Submissão e Desejo. Belém: Núcleo de Altos Estudos Amazônicos, Universidade Federal do Pará/Universidade do Estado do Pará.

VESSEY, M.; HUGGINS, G.; LAWLESS, M.; MCPHERSON, K. \& YEATES, D., 1983. Tubal sterilization: Findings in a large prospective study. British Journal of Obstetrics and Gynaecology, 90:203-209.

VIEIRA, E. M., 1994. A esterilização de mulheres de baixa renda em região metropolitana do sudeste do Brasil e fatores ligados à sua prevalência. Revista de Saúde Pública, 28:440-448.

VIEIRA, E. M., 1998. O arrependimento após a esterilização feminina. Cadernos de Saúde Pública, 14 (Sup. 1): 59-68.

WILCOX, L. S.; MARTINEZ-SCHNELL, B.; PETERSON, H. B.; WARE, J. H. \& HUGHES, J. M., 1992. Menstrual function after tubal sterilization. American Journal of Epidemiology, 135:1368-1381. 